\title{
LAS DOS VÍAS DEL REALISMO MORAL
}

El realismo moral es una de las dos posiciones dominantes en el debate metaético (la otra sería el antirrealismo), tanto en la actualidad como a lo largo del siglo XX. Sostiene dos grandes tesis. Por un lado, el significado de los juicios morales es apto para ser evaluado en términos de verdad y de falsedad. Esta es la denominada tesis del cognitivismo semántico. Por otro lado, la segunda tesis afirma que tales juicios hacen referencia a la existencia de hechos o propiedades morales, que actúan como condiciones de verdad de los juicios morales. Esta segunda tesis es conocida como la tesis ontológica. Nótese que, aunque estén presentadas separadamente, estas dos tesis están conceptualmente ligadas. 
Dentro del realismo moral, sin embargo, el camino se bifurca. Por un lado, encontramos el denominado naturalismo ético. Por otro, encontramos el realismo no-naturalista. Ambos comparten las dos tesis presentadas anteriormente y, por supuesto, el motto central del realismo moral: los criterios de corrección moral son independientes de las actitudes y preferencias de los agentes morales.

Sin embargo, y como veremos en lo que sigue, esto es lo único que comparten sin cambiar una coma ambas versiones del realismo moral. Los dos caminos que conducen a estas conclusiones no sólo no se parecen sino que, como veremos, en algunos pasos muestran que existen grandes tensiones conceptuales en el seno del realismo moral. Si estoy en lo cierto, existen dudas legítimas para pensar en una sola gran familia del realismo moral.

Como es sabido, G. E. Moore señaló que los predicados morales no son analizables en términos naturales. Si se acepta esta consideración, entonces sólo dos opciones parecen posibles: o bien los predicados morales aspiran a representar propiedades no naturales, o bien, sencillamente, puesto que en el mundo no existen nada más que propiedades naturales, y como los predicados morales no representan propiedades naturales no tienen contenido descriptivo y por tanto no son aptos para la verdad o la falsedad. La primera opción fue apoyada explícitamente por el propio Moore y por otros autores (Shafer-Landau, Stratton-Lake), quienes, bajo el rótulo del intuicionismo moral, han postulado la existencia de propiedades morales no naturales que actuarían como condiciones de verdad de los juicios morales. La segunda opción es la formulación clásica del emotivismo (Ayer, Stevenson): al proferir juicios que contienen predicados morales estamos expresando un sentimiento, una emoción o una actitud, pero en cualquier caso no estamos representando una parte de la realidad. El ataque de Moore tenía como gran diana una versión "primitiva" del naturalismo ético; aunque, contrariamente a la que seguramente era la pretensión inicial de Moore, el gran beneficiado del argumento de Moore ha resultado ser el emotivismo y no el intuicionismo moral (Darwall, Gibbard, Railton). 
Pero dejando a un lado que el argumento de Moore ha sido utilizado como recurso por parte del antirrealismo, el movimiento de Moore supone desvincular a la filosofía moral de cualquier contacto con los métodos propios de las ciencias empíricas. En otras palabras, para responder a la pregunta ¿qué debemos hacer? las ciencias empíricas resultan básicamente irrelevantes (Shafer-Landau).

El realismo moral naturalista, por el contrario, afirma que la ética debe ser abordada como son abordadas las ciencias naturales, puesto que su objeto de estudio forma parte de nuestra realidad y sus verdades son tan objetivas como aquellas que proporciona la física o la biología. Para descubrir tales verdades éticas, la ética debe aplicar los métodos de descubrimiento y justificación que son usados en otros ámbitos de las ciencias naturales (Boyd).

Así pues, una de las grandes diferencias entre realismo moral naturalista y realismo moral no naturalista parece ser de tipo epistemológico. Para el realismo moral antinaturalista la ética es un ámbito del saber totalmente distinto de la ciencia. Existirían cuatro tipos de razones por las cuales la ética no puede aplicar los métodos de descubrimiento y justificación tradicionalmente asociados a las ciencias naturales: 1) la ética carece de precisión y no puede llevar a cabo cuantificaciones ni ordenaciones cardinales, a diferencia de las ciencias reconocidas; 2) la ética se dedica a la evaluación práctica y a la recomendación, a diferencia de las ciencias reconocidas; 3 ) la ética se concentra en cuestiones causales únicamente de manera periférica; y 4) las verdades fundamentales de la ética parecen expresar proposiciones metafísicas, más que físicas, biológicas o químicas (Shafer-Landau).

Nótese que el hecho de negar cualquier rol a las ciencias empíricas en las cuestiones morales no implica que no existan verdades morales. Así, autores como W. D. Ross, T. Nagel, J. Rawls, J. McDowell o los mismos G. E. Moore o R. Shafer-Landau, rechazan explícita o, en algunos casos, implícitamente, que el método empírico-científico sea relevante para responder a la cuestión 'qué debemos hacer' y, sin embargo, con matices y énfasis distintos, todos ellos afirman la posibilidad de respuestas correctas o verdaderas a la cuestión 'qué 
debemos hacer'. Obviamente, si no hay un vínculo conceptual necesario entre naturalismo y realismo moral, también es posible conceptualmente el espacio ocupado por autores como A. Ayer, S. Blackburn o A. Gibbard, quienes también rechazan la participación de las ciencias empíricas en las cuestiones morales normativas y, precisamente debido a ello, consideran que no existe nada parecido a 'verdades morales'.

A los partidarios del realismo no naturalista, al rechazar el rol que los naturalistas asignan a la ciencia, no les queda más remedio que apelar a alguna forma de intuicionismo como herramienta epistemológica. Precisamente, las diversas formas de intuicionismo coinciden en al menos una de sus tesis: el rechazo de los métodos propios de las ciencias empíricas para llegar a conocer verdades morales. El camino para el conocimiento moral pasa por una comprensión profunda del contenido de los juicios morales. Por ejemplo: para saber que matar a un niño es moralmente incorrecto no hace falta investigación empírica alguna. Lo sabemos de antemano, a priori, porque entendemos qué significa que un niño muera a manos de alguien (Moore, ShaferLandau).

Para el realismo naturalista, sin embargo, el camino exitoso no es el de apelar a una misteriosa capacidad intuitiva del ser humano, sino el de acudir a la herramienta gnoseológica más potente, es decir, la ciencia. Así, R. Boyd considera que, contrariamente a lo presupuesto por el intuicionismo, las consideraciones teóricas juegan un papel fundamental en el campo práctico: los científicos modifican unidades de medida o procedimiento de descubrimiento con base en nuevos desarrollos teóricos. La estrategia de Boyd en este punto parece clara: si la ciencia -no la metodología ni la filosofía de a ciencia, sino la ciencia hecha por los científicos, esto es, por decirlo de alguna manera, la ciencia práctica- ha acudido en ocasiones a las teorías desarrolladas por los metodólogos para aumentar el conocimiento acerca de las entidades inobservables, por qué no podrían quienes se ocupan de la investigación del razonamiento práctico moral atender a los desarrollos teóricos acerca de las propiedades o hechos morales, es decir, a los debates en metaética. Boyd busca aquí rechazar la idea según la cual si la ética normativa tiene carácter eminentemente práctico, la teorización en las ciencias empíricas 
juega un papel totalmente irrelevante. Para Boyd esta es una concepción errónea, ya que hasta el momento los desarrollos teóricos han contribuido de manera notable al aumento del conocimiento acerca de las entidades inobservables. Si aceptamos como buena esta reconstrucción, entonces parece obvio que un aumento en el conocimiento empírico acerca de las propiedades morales -asumiendo que, si existen, serán entidades inobservables- repercutirá en cualquier investigación acerca del razonamiento práctico y jugará algún rol motivacional respecto de la pregunta 'qué debemos hacer'.

Pero para llevar a cabo este movimiento estratégico Boyd necesita tomar posición, previamente, respecto de una cuestión importante. Nótese que la reconstrucción de Boyd acerca de cómo avanza la ciencia presupone un punto de vista holístico acerca de la confirmación de las hipótesis científicas. $\mathrm{O}$ en otras palabras, supone el rechazo del fundacionalismo epistemológico. Por fundacionalismo, Boyd entiende aquella posición según la cual todo nuestro conocimiento está basado en última instancia en una serie de creencias fundacionales que ostentan una posición epistémicamente privilegiada y cuya verdad está garantizada a priori, más allá de investigaciones ulteriores.

La concepción fundacionalista es errónea, según el realismo naturalista, ya que el conocimiento aumenta acumulativamente por sucesivas aproximaciones y la evaluación de las teorías resulta, al fin y al cabo, un fenómeno social. Esto sugiere que la noción causal clave en epistemología regula las creencias aceptables o fiables (reliable) y no que produce estas creencias fiables o aceptables, tal y como el fundacionalismo supone. La conclusión de Boyd resultará a estas alturas evidente: la epistemología de las ciencias empíricas es una ciencia empírica; el método científico adolece de una contingencia radical, y su fundación es puramente a posterori.

Sin embargo, Boyd necesita un último paso para relacionar sus ideas acerca de cómo avanza realmente la ciencia y su defensa del realismo moral. La explicación tradicional del empirismo acerca del significado de los predicados morales, basada en definiciones operacionales o criterios de atribución, debe ser abandonada en favor de 
una nueva explicación naturalista acerca del significado de los predicados. Y esa "nueva" explicación naturalista resulta ser la teoría causal de la referencia, según la cual la referencia de un término es establecida por las conexiones causales entre el uso del término y las instancias de su referente (Kripke, Putnam). No nos interesa aquí examinar a fondo la teoría causal de la referencia ni su plausibilidad frente a sus rivales, sino que nos vale con poner de relieve lo siguiente: el naturalismo à la Boyd necesita esta teoría porque le permite tratar a los términos morales como términos naturales; así, H. Putnam, expresaba que las teorías naturalistas de la referencia y de las definiciones puede ser extendida al análisis del lenguaje moral; consecuencia de ello, si aceptamos ni que sea momentáneamente la teoría causal de la referencia aplicada a los términos morales, es que el significado, alcance y definición de los predicados morales será materia de investigación a posteriori.

Así pues, los dos puntos centrales de este tipo de realismo naturalista son: 1) existen hechos o propiedades morales; 2) la investigación que proporcionará el acceso a estos hechos o propiedades tendrá carácter a posteriori.

De este modo, vemos claramente la diferencia epistemológica entre realismo moral naturalista y realismo moral antinaturalista: mientras el realismo naturalista afirma que las verdades morales son conocidas a posteriori (Boyd, Kripke, Putnam, Railton), el realismo antinaturalista o intuicionismo moral, afirma que las verdades morales sólo pueden ser conocidas a priori (Shafer-Landau). La característica esencial tanto de las ciencias sociales como de las ciencias naturales es que ambas excluyen el conocimiento a priori de las verdades científicas fundamentales. Las verdades fundamentales de la ética, sin embargo, y según Shafer-Landau, pueden ser descubiertas a priori.

Para el realismo antinaturalista, por tanto, más allá de los desarrollos naturalistas de la ética, suena misterioso decir que la ética tiene carácter a posteriori cuando los debates entre naturalistas y antinaturalistas tienen lugar en el campo de la metafísica, aunque tengan implicaciones epistemológicas. 
Pero aquí me interesa recalcar la diferencia epistemológica fundamental entre realismo moral naturalista y realismo moral antinaturalista: mientras el primero afirma que el conocimiento moral es materia de investigación a posteriori, el segundo afirma que la gnoseología moral está gobernada por reglas a priori; el primero rechaza que las creencias sobre las que se funda la epistemología sean inmutables, al contrario, están sometidas a continuas evaluaciones y su plausibilidad depende, en parte, de que el conjunto de creencias sea consistente y su fiabilidad depende del mutuo apoyo entre ellas, mientras que para el antinaturalismo la herramienta epistemológica fundamental para el conocimiento moral es inmutable, i. e. la intuición.

Todas estas consideraciones ponen en tela de juicio que exista una gran familia metaética del realismo moral. Las diferencias entre realismo moral naturalista y realismo moral antinaturalista o intuicionismo son tan grandes sobre todo en los aspectos epistemológicos que considerar que pertenecen a una misma gran familia metaética "únicamente" porque ambos consideran que existen respuestas correctas a la pregunta "qué debemos hacer" genera un problema filosófico de calado.

Tampoco está muy claro que las dos principales vías del realismo moral compartan un mismo cuadro ontológico. ¿Cómo se relacionan el mundo natural con el mundo no-natural o moral? Esta relación entre el mundo moral y el mundo no moral se denomina superveniencia, y los críticos del realismo moral afirman que éste no da cuenta adecuadamente de la superveniencia del mundo moral sobre el mundo natural o no moral.

Ante esta crítica el camino realista vuelve a bifurcarse.

Por un lado el naturalismo ético reductivista ha afirmado que las propiedades morales son idénticas a las propiedades naturales; en otras palabras, que el mundo moral es idéntico al mundo natural. Debido a nuestro lenguaje, esta superveniencia puede quedar oculta. Por ejemplo, cuando hablamos del "planeta rojo" y cuando lo hacemos del planeta "Marte", nos estamos refiriendo al mismo objeto natural, aunque 
usemos distintos nombre para referirnos a él. De la misma manera, cuando hablamos de "lo moralmente correcto" y de "la maximización de las preferencias", por ejemplo, también nos referimos al mismo objeto natural, sólo que lo designamos con nombres distintos.

En oposición a esta versión se ha apostado por un realismo naturalista de tipo no reductivista. En primer lugar, de acuerdo con esta versión, la propiedad "moralmente correcto", por ejemplo, no es idéntica a una única propiedad natural. Si así fuera, entonces lo moralmente correcto únicamente se daría si se instanciara una propiedad natural, por ejemplo, "ser solidario"; esto es, una acción sería "moralmente correcta" si y sólo si fuera solidaria. Y, sin embargo, podemos encontrar otras propiedades naturales, tales como, por ejemplo, "ser bondadoso" o "no violento", que -por lo menos para algunos- ejemplificarían también lo "moralmente correcto". De manera que se puede estar obrando de manera moralmente correcta sin que ello signifique estar obrando solidariamente. Las propiedades morales, por tanto, son realizables de múltiples maneras distintas. De lo que se sigue que la propiedad moral ("lo moralmente correcto") no es idéntica a una sola propiedad natural ("ser solidario").

En segundo lugar, la dificultad de establecer relaciones de identidad entre propiedades naturales y propiedades morales ha llevado a algunos autores (Boyd, Sturgeon, Brink) a negar semejante relación de identidad y a ofrecer una explicación diversa: las propiedades morales son un género (genus) de propiedades naturales. Las propiedades morales, de acuerdo con esta idea, tendrían el mismo estatuto que las propiedades biológicas o geológicas, serían propiedades naturales realizadas o instanciadas en propiedades físicas, aunque no idénticas a estas últimas.

Por tanto, si las propiedades naturales son idénticas a las morales, entonces caemos en el reductivismo; en cambio, si consideramos que no son idénticas, adoptamos una posición antirreductivista. Estando así las cosas, Shafer-Landau extrae la conclusión según la cual naturalismo antirreductivista y antinaturalismo o intuicionismo comparten un mismo cuadro ontológico, el de una 
pluralidad de las propiedades (hay -por lo menos- dos tipos de propiedades: morales y naturales; para los reductivistas, en cambio, hay un solo tipo de propiedad: las propiedades naturales).

Así pues, tenemos tanto razones a favor y como razones en contra para agrupar al realismo naturalista y al realismo antinaturalista dentro de la misma familia metaética. Las razones a favor son, por así decir, su "presentación": ambos caminos del realismo moral creen poder estar en condiciones de mostrar que los enunciados morales son aptos para ser evaluados en términos de verdad y falsedad. Además, ambas vías afirman que aquello que hace verdaderos los enunciados morales son una suerte de propiedades morales cuya existencia es independiente de las actitudes o preferencias de los agentes morales. Pero si ahondamos en estas aparentes similitudes descubrimos que afloran diferencias conceptuales significativas. Las razones en contra son, por un lado, que mientras el realismo naturalista accede a esas verdades morales mediante una investigación a posteriori, el realismo antinaturalista hace lo propio pero a priori. Y, por otro lado, las propiedades morales que hacen verdaderos esos juicios morales, en el caso del realismo naturalista son idénticas a propiedades naturales, mientras que el realismo antinaturalista (y el denominado realismo naturalista antirreductivista) rechaza una ontología moral tan reductivista.

Estas diferencias ontológicas y epistemológicas hacen que agrupar dentro de la misma familia metaética a realismo naturalista y realismo antinaturalista abra un problema filosófico cuya resolución, tentativamente, pasará por determinar si son las razones a favor las más relevantes o bien lo son las razones en contra. 